\title{
Piwi-Pathway Alteration Induces LINE-1 Transposon Derepression and Infertility Development in Cryptorchidism
}

\author{
Faruk Hadziselimovic ${ }^{a}$ Nils O. Hadziselimovic ${ }^{a, b}$ Philippe Demougin ${ }^{b}$ \\ Gunthild Krey ${ }^{\mathrm{a}}$ Eduard Oakeley ${ }^{\mathrm{c}}$ \\ anstitute for Andrology, Liestal, b Life Sciences Training Facility, Biozentrum, University of Basel, and \\ 'Novartis Institutes for Biomedical Research, Basel, Switzerland
}

\section{Key Words}

Cell memory - Cryptorchidism · GTSF1 · Human · Infertility ·

LINE-1 $\cdot$ Mini-puberty $\cdot$ PIWIL4 $\cdot$ Transposon

\begin{abstract}
Spermatogonia contain processing bodies that harbor P-element-induced wimpy testis (Piwi) proteins. Piwi proteins are associated specifically with Piwi-interacting RNAs to silence transposable DNA elements. Loss-of-function mutations in the Piwi pathway lead to derepression of transposable elements, resulting in defective spermatogenesis. Furthermore, deletion of gametocyte-specific factor 1 (GTSF1), a factor involved in Piwi-mediated transcriptional repression, causes male-specific sterility and derepression of LINE1 (L1) retrotransposons. No previous studies have examined GTSF1, L1 and PIWIL4 expression in cryptorchidism. We examined transposon-silencing genes and L1 transposon expression in testicular biopsies with Affymetrix microarrays and immunohistology. Seven members of the Tudor gene family, 3 members of the DEAD-box RNA helicase family, and the GTSF1 gene were found to show significantly lower RNA signals in the high-infertility-risk group. In the immunohistochemical analysis, patients from the low-infertility-risk group showed coherently stronger staining for GTSF1 and PIWIL4 proteins and weaker staining for $\mathrm{L} 1$ transposon when com-
\end{abstract}

pared to the high-infertility-risk samples. These new findings provide first evidence consistent with the idea that infertility in cryptorchidism is a consequence of alterations in the Piwi pathway and transposon derepression induced by the impaired function of mini-puberty.

(c) 2015 S. Karger AG, Basel

Forty years ago, the ultrastructure of processing bodies (P-bodies), previously known as intermitochondrial cement, in spermatogonia of normal and cryptorchid boys was described [Seguchi and Hadziselimovic, 1974; Hadziselimovic, 1977]. At that time, no adequate interpretation was given regarding the observed P-body malformation in cryptorchid spermatogonia [Hadziselimovic, 1977].

Today we know that P-bodies are cytoplasmic organelles containing dynamic aggregates of specific mRNAs and proteins [Castañeda et al., 2011]. P-bodies exhibit a complex mechanism regulating the organization and function of P-element-induced wimpy testis (Piwi) proteins and small Piwi-interacting RNAs in transposon-silencing pathways. This P-body mechanism includes a methylation-directed protein-protein interaction, mediated by germline Tudor domain proteins and methylated Piwi family proteins [Chen et al., 2009].

\begin{tabular}{|c|c|}
\hline KARGER 125:s & $\begin{array}{l}\text { (c) } 2015 \text { S. Karger AG, Basel } \\
1661-5425 / 15 / 0092-0098 \$ 39.50 / 0\end{array}$ \\
\hline $\begin{array}{l}\text { E-Mail karger@karger.com } \\
\text { www.karger.com/sxd }\end{array}$ & $\begin{array}{l}\text { This is an Open Access article licensed under the terms of the } \\
\text { Creative Commons Attribution-NonCommercial 3.0 Un- } \\
\text { ported license (CC BY-NC) (www.karger.com/OA-license), } \\
\text { applicable to the online version of the article only. Distribu- } \\
\text { tion permitted for non-commercial purposes only. }\end{array}$ \\
\hline
\end{tabular}

Prof. Dr. Faruk Hadziselimovic Kindermedizinisches Zentrum Bahnhofplatz 11

CH-4410 Liestal (Switzerland)

E-Mail liestal@kindermedizin-zentrum.ch 
Also, a recent report has shown that the gametocytespecific factor 1 (GTSF1) is an essential factor in Piwimediated transcriptional repression [Dönertas et al., 2013]. In addition, the androgen-dependent RNA helicase, DEAD (Asp-Glu-Ala-Asp)-box polypeptide 4 (DDX4) [Stanton et al., 2012], was found to be essential for the organization and presumably for the function of P-bodies [Kuramochi-Miyagava et al., 2010]. Thus, silencing transposable DNA elements requires intact Pbodies that harbor Piwi proteins specifically associated with Tudor family genes (TDRD), DEAD-box RNA helicase (DDX), and GTSF1. This transposon-silencing mechanism maintains the integrity of the genome and promotes the development of gametes. Malfunction of the Piwi-interacting RNA pathway leads to derepression of multiple transposon families in mouse germ cells and is associated with sterility [Aravin et al., 2007]. It is postulated that sterility is most likely caused by the occurrence of double-strand DNA breaks generated by transposition events [Klattenhoff et al., 2007]. In a previous study, we found impaired expression of DDX4, MAEL, MOV10L1, PIWIL2, PIWIL4, and TDRD9 genes in boys with cryptorchidism, who exhibited a high infertility risk (HIR) due to altered mini-puberty function [Hadziselimovic et al., 2011a]. That finding indicated that gene instability is induced by impairment in the endogenous system that defends against transposons; we hypothesized that this instability may contribute to the development of azoospermia.

The objective of the present study was to determine whether alterations in transposon-silencing gene expression and LINE 1 (L1) transposon derepression were correlated to infertility in cryptorchidism. Therefore, we analyzed gene expression and protein levels in testicular biopsies from boys with cryptorchidism and compared the expression patterns between HIR and LIR groups.

\section{Patients and Methods}

\section{Testicular Biopsies and Patient Groups}

All patients had an extensive clinical examination, and we could not find any clinical signs of developmental malformations or syndromes. Furthermore, all patients had normal thyroid screening, and no features of hypopituitarism were discernible. At surgery, the testicular position in HIR patients was 1 abdominal and 6 tubercle, and in low-infertility-risk (LIR) patients, 1 inguinal and 11 tubercle. One patient from the HIR group and one from the LIR group had hormone treatments with LH-RH 5 months prior to surgery. At our institution, it is routine practice to perform a testicular biopsy during surgery for undescended testes. We have found that testicular biopsies provide useful information about the future quality of semen, and this information may be used to identify patients with atypical spermatogonia or carcinoma in situ. A cryptorchid testis is defined as a testis localized outside the scrotum, which is not amenable to being moved into a stable scrotal position. In the present study, for microarray analysis, we included 19 rice-grain-sized testicular biopsies. The HIR group $(n=7)$ is characterized by a lack of Ad spermatogonia and a total germ cell count $<0.2$ spermatogonia/tubule. The LIR group $(n=12)$ is characterized by $\geq 0.1$ Ad spermatogonia per tubular cross section and a total germ cell count $\geq 0.6$ spermatogonia/tubule. The 2 groups were comparable in age, with mean ages of 2.9 years (95\% CI, 0.55.84) for the HIR group and 3.6 years (95\% CI, 2.78-4.41) for the LIR group. The biopsy specimens were immediately fixed in $3 \%$ glutaraldehyde containing PBS ( $\mathrm{pH}$ 7.6). Post-fixation was performed in $1 \% \mathrm{OsO}_{4}$. Biopsies were embedded in Epon 812. Semithin sections were stained with toluidine blue and analyzed with a Zeiss-Axio-Scope light microscope. Six-hundred-ångström-thick silver sections were cut with a Reichert ultramicrotome, and stained with uranyl acetate and lead citrate. Ultrathin sections were analyzed with a Zeiss EM 9A electron microscope. RNA isolation, microarray analysis and quantitative real-time PCR examination were previously published [Hadziselimovic et al., 2009, 2011b].

\section{Statistical Analysis and Interpretation of Microarray Data}

Data analysis and gene filtering were performed using R/Bioconductor [Gentleman et al., 2004]. Signal condensation was performed using only the RNA from the Bioconductor Affy package. Differentially expressed genes were identified using the Benjamini-Hochberg false discovery rate correction implemented in the LIMMA package and adjusted with the false discovery rate method [Wettenhall and Smyth, 2004]. We selected probe sets with a $\log _{2}$ average contrast signal of at least 4.1 , an adjusted $\mathrm{p}$ value $<0.05$, and an absolute $\log _{2}$-fold change $>0.585$ ( 1.5 -fold in linear space). Complete statistical analysis details were previously published [Hadziselimovic et al., 2011b].

\section{Antibody Analysis}

For immunohistochemical analysis, Epon was removed from the tissue sections. The sections were treated with $2 \%$ bovine serum albumin to reduce nonspecific binding and then incubated with primary antibody overnight at $4^{\circ} \mathrm{C}$. All samples were washed with PBS. We analyzed L1 (sc-67197), GTSF1 (sc-240545), PIWIL4 (sc-67593) primary antibody (Santa Cruz Biotechnology Inc.), and INSL3 (ab65981) (Abcam). Secondary antibodies, labeled with polymer-horseradish peroxidase (goat polyclonal, antirabbit IgG, mouse IgG and IgM) (Abcam) were used to detect binding of the primary antibody. The chromogenic reaction was developed by adding a freshly prepared solution of 3.3-diaminobenzidine solution (DAB + chromogen; DAKO). The DAB reaction was terminated by washing in Tris-buffered saline $(0.005 \mathrm{M}$ TBS and $0.85 \mathrm{M} \mathrm{NaCl}, \mathrm{pH}$ 7.6). To visualize the histology of testicular cells, the samples were counterstained with toluidine blue. Antibody binding was indicated by a brown precipitate. Controls for nonspecific binding of the secondary antibody were performed in all experiments by omitting the primary antibody; these consistently yielded no signal within the seminiferous epithelium or the interstitial space. The interstitial and intratubular staining observed in the presence of the primary antibody was considered to be nonspecific because it was not associated with, or localized within, a particular cell type. 
Table 1. Transcript signature of differentially expressed genes involved in the Piwi pathway and germ cell development in HIR and LIR groups

\begin{tabular}{lllll}
\hline Gene $^{\mathrm{a}}$ & Affymetrix No. & HIR & LIR & p value $^{\mathrm{b}}$ \\
\hline TDRD1 & 221018 s-at & 3.08 & 4.1 & 0.0003 \\
TDRD2 (TDRKH) & 223530 -at & 4.85 & 6.14 & 0.01 \\
TDRD3 & 214028 -at & 6.6 & 7.05 & n.s. \\
TDRD4 (RNF17) & 220270 -at & 4.17 & 5.40 & 0.015 \\
TDRD5 & 231104 -at & 3.78 & 4.92 & 0.015 \\
TDRD6 & 232692 -at & 5.1 & 6.79 & 0.0003 \\
TDRD7 & 213361 -at & 6.78 & 7.66 & n.s. \\
TDRD8 (STK31) & 223883 s-at & 4.4 & 8.25 & $8.24 \mathrm{E}^{-0.5}$ \\
TDRD9 & 228285 -at & 4.7 & 6.52 & 0.009 \\
TDRD10 & 231371 -at & 5.25 & 6.17 & n.s. \\
TDRD11 & 2022 -at16 & 8.51 & 8.6 & n.s. \\
TDRD12 & 215356 -at & 4.69 & 4.54 & n.s. \\
DDX4 & 221630 -at & 3.47 & 7.05 & $8.24 \mathrm{E}^{-2}$ \\
DDX25 & 219945 -at & 4.39 & 5.86 & 0.001 \\
DDX43 & 220004 -at & 4.76 & 7.24 & 0.0002 \\
GTSF1 & 227711 -at & 4.6 & 7.27 & 0.0001 \\
\hline
\end{tabular}

${ }^{\mathrm{a}} \log _{2}$ signal intensity; average contrast signal median values. ${ }^{\mathrm{b}}$ Adjusted for all values. Significance was accepted at $\mathrm{p}<0.05$. n.s. $=$ Not significant.
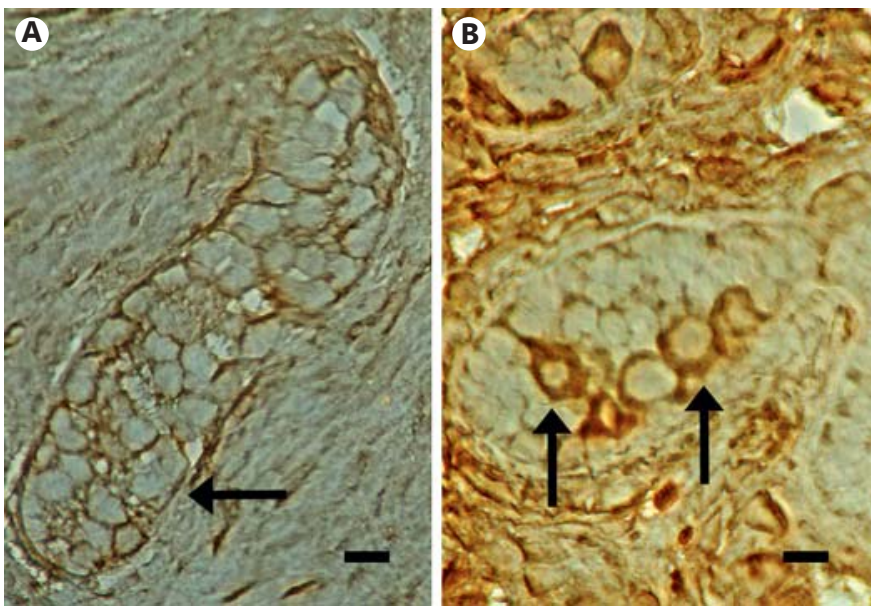

Fig. 1. PIWIL4. A Weak PIWIL4 protein staining localized in the germ cells of HIR testis (arrow). In all cases, antibody binding was visualized using peroxidase as a substrate to generate brown color. Sections were counterstained with toluidine blue. B LIR testis. Intensive PIWIL4 staining is observed in the cytoplasm of spermatogonia (arrows). Scale bars $=10 \mu \mathrm{m}$.
For immunohistochemical analysis, 12 biopsies from the LIR group and 7 from the HIR group were analyzed. In addition, we analyzed 6 biopsies from contralateral descended testis, 3 from each group. Two examiners (F.H. and G.K.) independently analyzed the stain intensity in blind fashion. The incidence of weak (+ or ++$)$ and strong $(+++$ or ++++$)$ stain intensity was recorded and compared. Experimental design, biomaterials and treatments, reporters, staining, imaging data, and image characterization were performed in compliance with the minimum information specification for immunohistochemistry experiments [Deutsch et al., 2008].

\section{Ethics}

In accordance with the Declaration of Helsinki, all aspects of this study were approved by the Institutional Review Board and the Independent Ethics Committee of the Children's Clinic in Liestal. Approval was provided for research involving the use of material (data records or biopsy specimens) that had been collected for nonresearch purposes.

\section{Results}

\section{RNA Profiling}

GTSF1 gene expression was at the limit of detection in HIR samples, but was strongly expressed in LIR samples. Twelve TDRD transcripts (table 1) are expressed in prepubertal spermatogonia. We found only weak TDRD1 and TDRD5 expression in the LIR group and no TDRD1 or TDRD5 expression in the HIR group. TDRD1 is known to be required for spermatogenesis, and it is strongly expressed in the testis after puberty [Lardenois et al., 2010]. The TDRD2 (or TDRKH) gene was expressed in the LIR group but showed only weak expression in the HIR group. $T D R D 3$, the ubiquitously expressed, transcriptional coactivator that binds methylarginine to histone tails, showed strong expression in both HIR and LIR groups. TDRD4 (or RNF17) was expressed at the limit of assay detection in the HIR group, but they were reasonably expressed in the LIR group. The largest difference between the groups was in the expression of TDRD8 (or STK31). Clear differences between the groups were also observed in the expression levels of TDRD6 and TDRD9. Notably, the 2 groups showed equivalent expression levels for TDRD10, TDRD11 (or SND1) and TDRD12. The TDRD7 gene is essential for early spermatid differentiation, and it is a master regulator in the biogenesis of chromatoid bodies [Tanaka et al., 2011]. TDRD7 showed strong expression in all testes studied.

The testosterone-dependent RNA helicase, DDX4, which is essential for the organization of intermitochondrial cement, was not expressed in the HIR group, but was strongly expressed in the LIR group. Furthermore, gonadotropin-dependent DDX25 helicase [Tsai-Morris et al., 2004] as well as DDX43 RNA helicases were differentially expressed in the HIR and LIR groups (table 1). 

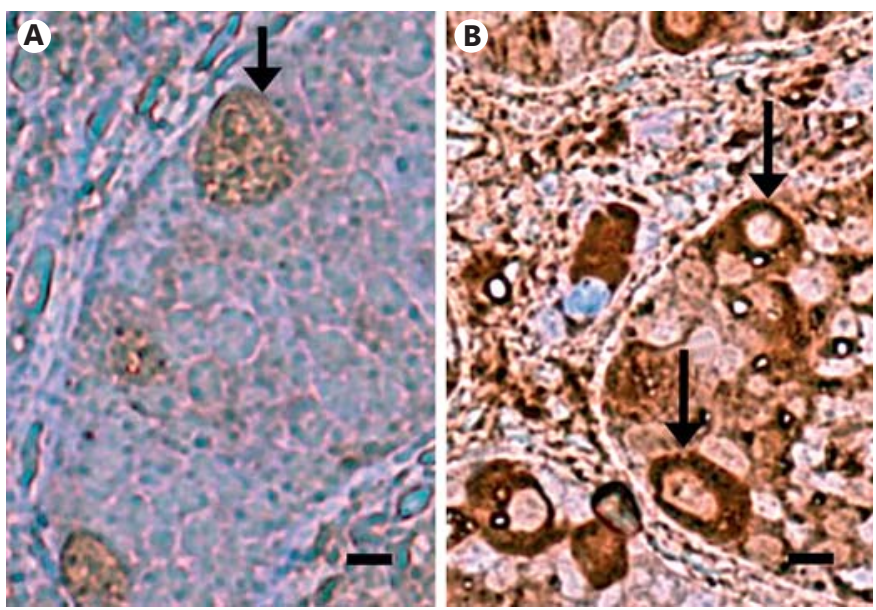

Fig. 2. GTSF1. A In contrast to strong accumulation of the GTSF1 protein in LIR germ cells, a weak brown staining of the GTSF1 protein is found in the germ cells of HIR testis (arrow). B GTSF1 is strongly stained in the germ cells of LIR testis (arrows). For staining, see figure 1 . Scale bars $=10 \mu \mathrm{m}$.
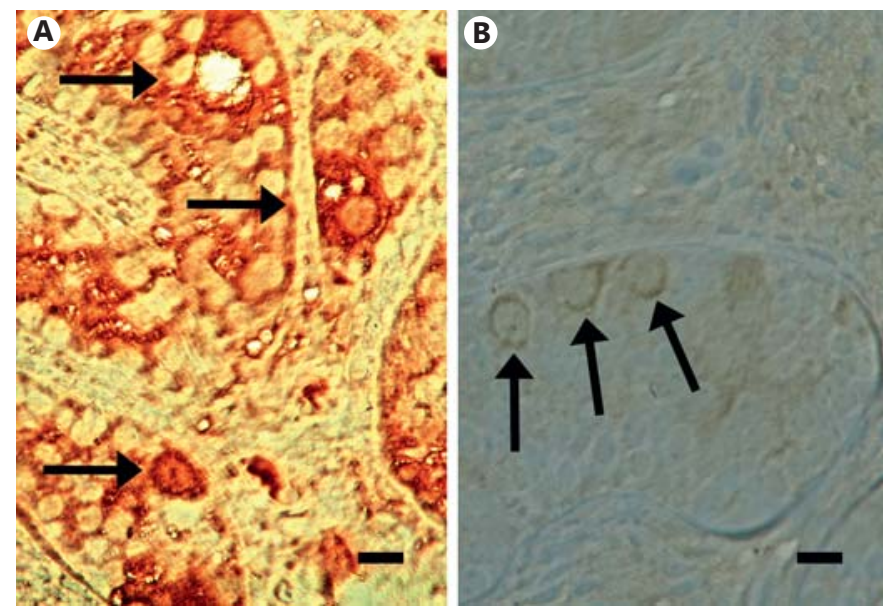

Fig. 4. LINE-1. Contralateral descended testis in unilateral cryptorchid boy. A Strong LINE-1 peroxidase staining (arrows) in spermatogonia from contralateral descended testis (HIR group). B Weak immunohistochemical staining for LINE-1 proteins in the germ cells of contralateral descended LIR testis (arrows). For staining, see figure 1 . Scale bars $=10 \mu \mathrm{m}$.

\section{Immunohistochemical Validation}

PIWIL4 protein was strongly expressed in the LIR group and weakly stained in the HIR group (fig. 1). The GTSF1 protein was found in both groups of cryptorchid testes, but the staining was stronger in the LIR group than in the HIR group (fig. 2). The L1 protein was detected in
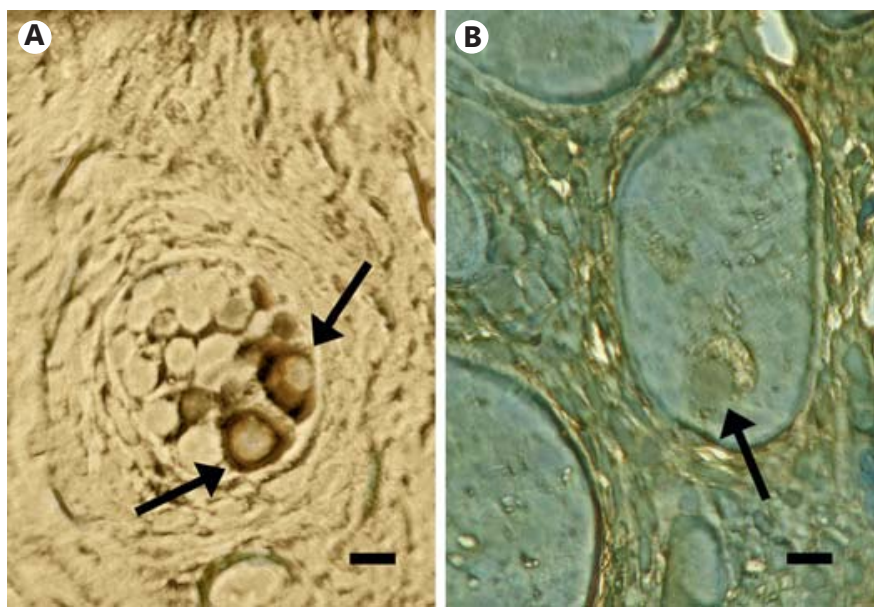

Fig. 3. LINE-1. Cryptorchid testis. A Intra-abdominal (HIR) testis with small atrophied tubule and extensive interstitial fibrosis. Spermatogonia show a strong immunohistochemical staining for LINE-1 retrotransposons (arrows). B In contrast, spermatogonia from LIR testes show a weak immunohistochemical staining (arrow). For staining, see figure 1 . Scale bars $=10 \mu \mathrm{m}$.

the germ cell cytoplasm in all testes analyzed. However, more intense staining $(+++$ and ++++$)$ was observed in HIR than in LIR spermatogonia (+ or ++ ) (fig. 3,4$)$. Immunohistochemical data are credible because the control gene INSL3, which shows no differential mRNA expression, remains also constant at protein level (fig. 5). Moreover, altered P-body morphology was found in most spermatogonia in the HIR group (fig. 6).

\section{Discussion}

This study shows that males with cryptorchidism and impaired mini-puberty have alterations in Piwi pathway gene expression, which are different in HIR and LIR individuals; thus, these alterations are implicated in the development of infertility. In turn, altered function of malformed P-bodies failed to repress transposon activity.

It is widely accepted that exposure of the cryptorchid testis to abnormally high temperatures induces germ cell loss and infertility [Setchell, 1998]. However, the temperature effect cannot explain several findings. For example, both HIR and LIR males with unilateral cryptorchidism have one descended testis that escapes the temperature influence; however, in identically aged groups, surgery produced completely different fertility outcomes in HIR and LIR individuals [Hadziselimovic and Hoecht, 2008]. On the other hand, early orchidopexy, performed before 

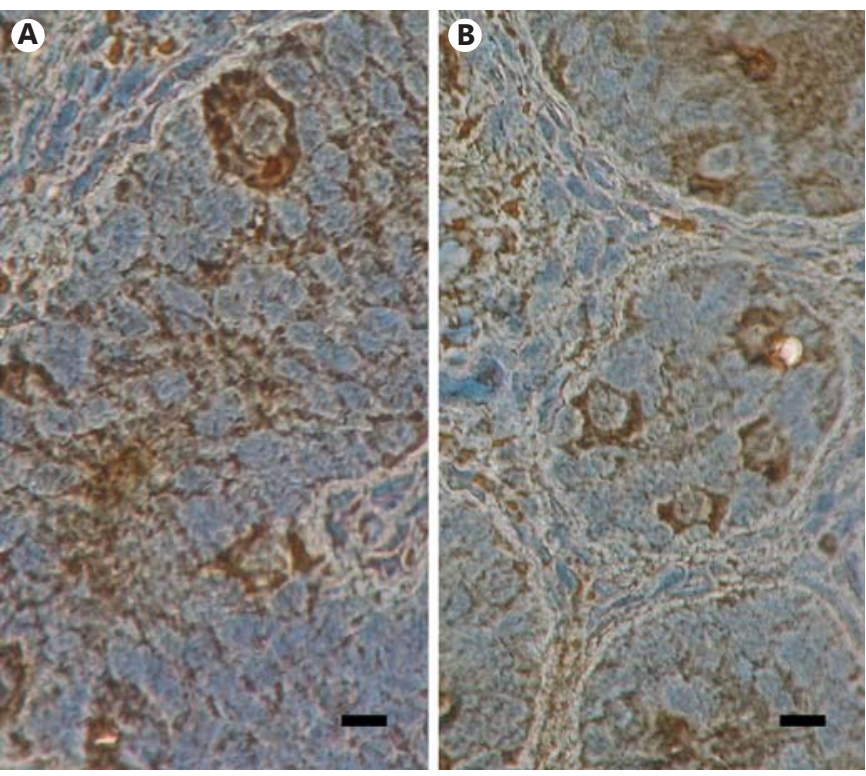

Fig. 5. INSL3. Identical INSL3 immunohistochemical protein staining in HIR (A) and LIR (B) spermatogonia (brown) validates identical INSL3 transcripts levels observed in both groups. The $\log _{2}$ intensity of INSL3 gene expression was 8.96 in HIR and 8.59 in LIR testes. Scale bars $=10 \mu \mathrm{m}$.

assumed temperature-induced testicular damage, did not improve fertility in one third of cryptorchid males [Hadziselimovic and Herzog, 2001]. These failures were explained by impaired transformation of gonocytes into Ad spermatogonia, which resulted from alterations in EGR4 gene expression and gonadotropin as well as testosterone secretion during mini-puberty [Hadziselimovic et al., 2005, 2009]. Another example of infertility that could not be explained by temperature exposure was evidenced by the development of boys with deficiencies in the steroid 5-alpha reductase gene, $S R D 5 A 2$, which leads to bilateral cryptorchidism. These boys exhibited normal spermatogonia numbers and normal differentiation during the entire prepubertal period. Those findings were in sharp contrast to observations in boys with normal SRD5A2 levels that developed isolated bilateral cryptorchidism and showed identical testicular malpositioning [Hadziselimovic and Dessouky, 2008]. Because the testicular positions in these 2 groups of boys are identical, their testes would be expected to have experienced the same temperature exposure. Therefore, if temperature were the only explanation for a massive germ cell loss in bilateral cryptorchidism, the 2 groups should have exhibited identical germ cell loss. However, this was not the case [Hadziselimovic and Dessouky, 2008]; thus, at the
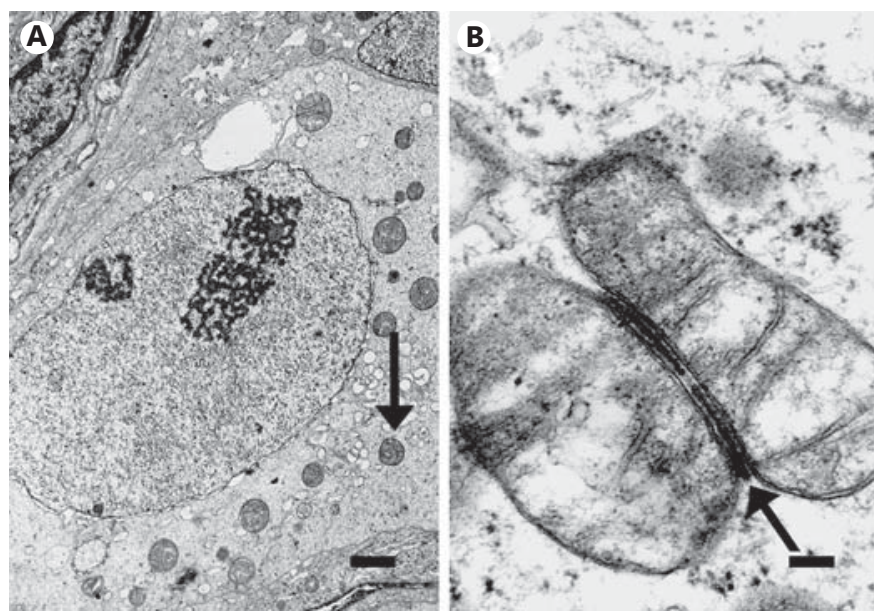

Fig. 6. P-body ultrastructure. A Ap spermatogonium from testis of an HIR boy. P-bodies are missing (arrow). Scale bar $=1 \mu \mathrm{m}$. B Normal ultrastructure of P-body of a 5-year-old boy showing intermitochondrial cement regularly distributed between mitochondria of a crysta type (arrow). Scale bar $=0.1 \mu \mathrm{m}$.

level of spermatogonia, temperature appears to have only a negligible effect.

Based on our results, we propose that an insufficient endogenous defense system against transposons may be responsible for massive germ cell death and infertility.

Selfish mobile elements, or transposons, subject the genome to severe biological threat by moving to positions that alter important genome information and organization [Kazazian, 2004]. Epigenetic reprogramming, including the erasure and resetting of DNA methylation, takes place in primordial germ cells. This reprogramming is likely to be important in preventing the passage of DNA methylation defects from one generation to the next [Castañeda et al., 2011; Bortvin, 2013]. However, the most important role for epigenetic reprogramming is to restore the developmental potency of the germline and to prepare the genome for the establishment of male-specific DNA methylation patterns in imprinted genes [Bortvin, 2013].

PIWI, DDX and TUDOR family genes are implicated in germline development because they participate in controlling transposons through the Piwi-small RNA silencing pathway. This pathway for transposon control is intimately integrated into germ cell development [Tanaka et al., 2011; Chuma and Nakano, 2012]. Piwi-associated 
small RNAs can act independently or they can cooperate with chromatin modifications to achieve long-lasting effects necessary for cellular memory and transgenerational inheritance [Stuwe et al., 2014]. PIWIL4 is predominantly expressed in the mouse spermatogonia during the period of de novo DNA methylation [Bortvin, 2013]. Earlier studies have revealed that the loss of Piwi-like genes, MILI/PIWIL2 and MIWI2/PIWIL4, or the loss of TUDOR genes causes the overexpression of L1 transposons to levels much higher than the levels detected in wild-type testes [Aravin et al., 2007; Kuramochi-Miyagawa et al., 2008; Shoji et al., 2009]. Testosterone plays a key role in the regulation of spermatogenesis [Walker, 2010]. Recently it has been shown that testosterone alters testicular function through regulation of the Piwi-interacting RNA expression [Kang et al., 2014]. Mutant mice with insufficient testosterone secretion expressed less Miwi/ Piwill, a transposon-silencing gene [Gill-Sharma et al., 2012]. Moreover, mice deficient in each of the genes essential for silencing the $\mathrm{L} 1$ retrotransposons were sterile [Chuma and Nakano, 2012; Bortvin, 2013].

We found that HIR individuals with altered hypothalamic-pituitary-gonadal axis function show little or no expression of the PIWIL4 protein [Hadziselimovic et al., 2011a] and 7 of the 12 TDRD family members that are important for spermatogenesis (table 1). This deficiency is accompanied by underexpression of DDX 4 and DDX25 genes, which are dependent on gonadotropin and testosterone stimulation. Interestingly, sterile mice with Vasa ( $D d x 4)$ deficiencies had malformed P-bodies with an ultrastructural appearance identical to that observed in our previous study [Hadziselimovic, 1977; Kuramochi-Miyagawa et al., 2010]. Accordingly, we confirm that impaired expression of key genes in the Piwi pathway and derepression of L1 retrotransposons accompanied by decreased PIWIL4 protein synthesis in the HIR group is involved in the development of infertility in human cryptorchidism.

GTSF1 is a member of the evolutionarily conserved UPF0224 gene family, which is involved in retrotransposon suppression and has been found to be expressed predominantly in germ cells. It has also been demonstrated that GTSF1-null mice exhibited male-specific sterility. Cells lacking GTSF1 contained nuclear Piwi proteins that were loaded with small RNAs, but the transposon-silencing capacity was ablated [Dönertas et al., 2013]. Our observation that HIR testes show insufficient GTSF1 expression suggests that infertility may be additionally associated with a lack of GTSF1 expression contributing to the development of L1 overexpression.

In conclusion, our results suggest that germ cell maldevelopment in cryptorchidism is accompanied by a hormonal imbalance and a perturbation in germ cell-specific gene expression during mini-puberty. An HIR group of cryptorchid boys exhibited altered Piwi-pathway gene expression, which permits overexpression of transposons and culminates in the development of infertility or sterility. This novel observation implies that the growth and formation of P-bodies during mini-puberty are regulated by hormones, and that P-bodies contribute to the establishment of germ cell memory and male-specific DNA methylation pathways.

\section{References}

Aravin AA, Sachidanandam R, Girard A, FejesToth K, Hannon GJ: Developmentally regulated piRNA clusters implicate MILI in transposon control. Science 316:744-747 (2007).

- Bortvin A: Piwi-interacting RNAs (piRNAs) - a mouse testis perspective. Biochemistry (Mosc) 78:592-602 (2013).

Castañeda J, Genzor P, Bortvin A: piRNAs, transposon silencing, and germline genome integrity. Mutat Res 714:95-104 (2011)

-Chen C, Jin J, James DA, Adams-Cioaba MA, Park JG, et al: Mouse Piwi interactome identifies binding mechanism of Tdrkh Tudor domain to arginine methylated Miwi. Proc Natl Acad Sci USA 106:20336-20341 (2009).

Chuma S, Nakano T: piRNA and spermatogenesis in mice. Phil Trans R Soc Lond B Biol Sci 368: 20110338 (2012).

Piwi-Pathway Alteration in

Cryptorchidism
Brazm, ification for in situ hybridization and immunohistochemistry experiments (MISFISHIE). Nat Biotechnol 26:305-312 (2008).

Dönertas D, Sienski G, Brennecke J: Drosophila Gtsf1 is an essential component of the Piwimediated transcriptional silencing complex. Genes Dev 27:1693-1705 (2013).

-Gentleman RC, Carey VJ, Bates DM, Bolstad B, Dettling $\mathrm{M}$, et al: Bioconductor: open software development for computational biology and bioinformatics. Genome Biol 5:R80 (2004).

Gill-Sharma M, Choudhuri J, Ansari MA, D’Souza S: Putative molecular mechanism underlying sperm chromatin remodelling is regulated by reproductive hormones. Clin Epigenetics 4:23 (2012).
Hadziselimovic F: Cryptorchidism. Ultrastructure of normal and cryptorchid testis development. Adv Anat Embryol Cell Biol 53:3-71 (1977).

-Hadziselimovic F, Dessouky N: Differences in testicular development between 5 alpha-reductase 2 deficiency and isolated bilateral cryptorchidism. J Urol 180:1116-1120 (2008).

Hadziselimovic F, Hadziselimovic NO, Demougin P, Krey G, Hoecht B, Oakeley EJ: EGR4 is a master gene responsible for fertility in cryptorchidism. Sex Dev 3:253-263 (2009).

Hadziselimovic F, Hadziselimovic NO, Demougin P, Krey G, Oakeley EJ: Deficient expression of genes involved in the endogenous defense system against transposons in cryptorchid boys with impaired mini-puberty. Sex Dev 5:287-93 (2011a). 
Hadziselimovic F, Hadziselimovic NO, Demougin P, Oakeley EJ: Testicular gene expression in cryptorchid boys at risk of azoospermia. Sex Dev 5:49-59 (2011b).

Hadziselimovic F, Herzog B: The importance of both an early orchidopexy and germ cell maturation for fertility. Lancet 358:1156-1157 (2001).

Hadziselimovic F, Hoecht B: Testicular histology related to fertility outcome and postpubertal hormone status in cryptorchidism. Klin Padiatr 220:302-307 (2008).

-Hadziselimovic F, Zivkovic D, Bica DT, Emmons LR: The importance of mini-puberty for fertility in cryptorchidism. J Urol 174:15361639 (2005).

Kang HJ, Moon MJ, Lee HY, Han AW: Testosterone alters testis function through regulation of piRNA expression in rats. Mol Biol Rep 41: 6729-6735 (2014).

Kazazian HH Jr: Mobile elements: drivers of genome evolution. Science 303:1626-1632 (2004).

-Klattenhoff C, Bratu DP, McGinnis-Schultz N, Koppetsch BS, Cook HA, Theurkauf WE: Drosophila rasiRNA pathway mutations disrupt embryonic axis specification through activation of an ATR/Chk2 DNA damage response. Dev Cell 12:45-55 (2007).
Kuramochi-Miyagawa S, Watanabe T, Gotoh K, Takamatsu K, Chuma S, et al: MVH in piRNA processing and gene silencing of retrotransposons. Genes Dev 24:887-892 (2010).

Kuramochi-Miyagawa S, Watanabe T, Gotoh K, Totoki Y, Toyoda A, et al: DNA methylation of retrotransposon genes is regulated by Piwi family members MILI and MIWI2 in murine fetal testes. Genes Dev 22:908-917 (2008).

Lardenois A, Gattiker A, Collin O, Chalmel F, Primig M: GermOnline 4.0 is a genomics gateway for germline development, meiosis and the mitotic cell cycle. Database (Oxford) 2010:baq030 (2010).

Seguchi H, Hadziselimovic F: Ultramicroscopic studies on the seminiferous tubule in children from birth to puberty. I. Spermatogonia development [in German]. Verh Anat Ges 68: 133-148 (1974).

Setchell BP: The Parkers Lecture. Heat and the testis. J Reprod Fertil 114:179-194 (1998).

Shoji M, Tanaka T, Hosokawa M, Reuter M, Stark A, et al: The TDRD9-MIWI2 complex is essential for piRNA-mediated retrotransposon silencing in the mouse male germline. Dev Cell 17:775-787 (2009).
Stanton PG, Sluka P, Foo CF, Stephens AN, Smith $\mathrm{AI}$, et al: Proteomic changes in rat spermatogenesis in response to in vivo androgen manipulation; impact on meiotic cells. PlosOne 7:e41718 (2012).

Stuwe E, Tóth KF, Aravin AA: Small but sturdy: small RNAs in cellular memory and epigenetics. Genes Dev 28:423-431 (2014).

Tanaka T, Hosokawa M, Vagin VV, Reuter M, Hayashi E, et al: Tudor domain containing 7 (Tdrd7) is essential for dynamic ribonucleoprotein (RNP) remodeling of chromatoid bodies during spermatogenesis. Proc Natl Acad Sci USA 26:10579-10584 (2011).

Tsai-Morris CH, Sheng Y, Lee E, Lei KJ, Dufau ML: Gonadotropin-regulated testicular RNA helicase (GRTH/Ddx25) is essential for spermatid development and completion of spermatogenesis. Proc Natl Acad Sci USA 101: 6373-6378 (2004).

Walker WH: Non-classical action of testosterone and spermatogenesis. Phil Trans R Soc Lond B Biol Sci 365:1557-1569 (2010).

Wettenhall JM, Smyth GK: limmaGUI: a graphical user interface for linear modeling of microarray data. Bioinformatics 20:3705-3706 (2004). 